Article

\title{
Dihalogen and Pnictogen Bonding in Crystalline Icosahedral Phosphaboranes
}

\author{
Jindřich Fanfrlík ${ }^{1, *(1)}$ and Drahomír Hnyk ${ }^{2, *}$ \\ 1 Institute of Organic Chemistry and Biochemistry of the Czech Academy of Sciences, Flemingovo nam. 2, \\ 16610 Prague 6, Czech Republic \\ 2 Institute of Inorganic Chemistry of the Czech Academy of Sciences, 25068 Husinec-Řež, Czech Republic \\ * Correspondence: fanfrlik@uochb.cas.cz (J.F.); hnyk@iic.cas.cz (D.H.)
}

Received: 6 September 2018; Accepted: 9 October 2018; Published: 13 October 2018

\begin{abstract}
Noncovalent interactions in the single crystal of 3,6-Cl - -closo-1,2- $\mathrm{P}_{2} \mathrm{~B}_{10} \mathrm{H}_{8}$ and in the crystal of closo-1,7- $\mathrm{P}_{2} \mathrm{~B}_{10} \mathrm{Cl}_{10}$ toluene were analyzed by means of quantum chemical computations. The crystal packing in the second crystal was dominated by numerous $\mathrm{B}-\mathrm{Cl} \cdots \mathrm{Cl}-\mathrm{B}$ dihalogen and strong B-P $\cdots \pi$ pnictogen bonds, the latter of which were characterized by a small length of $3.08 \AA$ and a large interaction energy value, exceeding $-10 \mathrm{kcal} \mathrm{mol}^{-1}$.
\end{abstract}

Keywords: sigma hole; heteroborane; co-crystal

\section{Introduction}

Phosphorus atoms can be relatively easily incorporated into the icosahedral closo- $\mathrm{B}_{12} \mathrm{H}_{12}{ }^{2-}$ skeleton, which is achieved experimentally by reacting a boron hydride with an open pentagonal belt, e.g. $\mathrm{B}_{10} \mathrm{H}_{14}$, with $\mathrm{PCl}_{3}[1,2]$. Such a reaction yields closo- $1,2-\mathrm{P}_{2} \mathrm{~B}_{10} \mathrm{H}_{10}$ and its mono- and di-chloro derivatives. Among them, 3,6- $\mathrm{Cl}_{2}$-closo-1,2- $\mathrm{P}_{2} \mathrm{~B}_{10} \mathrm{H}_{8}(\mathbf{1})$ has been crystallized after separation from the reaction mixture. The parent phosphaborane can be thermally rearranged to obtain the isomeric closo-1,7- $\mathrm{P}_{2} \mathrm{~B}_{10} \mathrm{H}_{10}$ [3]. However, when the pyrolysis reaction of $\mathrm{B}_{2} \mathrm{Cl}_{4}$ with $\mathrm{PCl}_{3}$ takes place, the terminal hydrogens of the latter cage are completely substituted by chlorines, resulting in closo-1,7- $\mathrm{P}_{2} \mathrm{~B}_{10} \mathrm{Cl}_{10}$ (2). The molecular diagrams of $\mathbf{1}$ and $\mathbf{2}$ with numbering are shown in Figure 1. Compound 2 is prone to crystallization with toluene, yielding crystals of $2 \bullet \mathrm{C}_{6} \mathrm{H}_{5} \mathrm{CH}_{3}$ in this process [4].

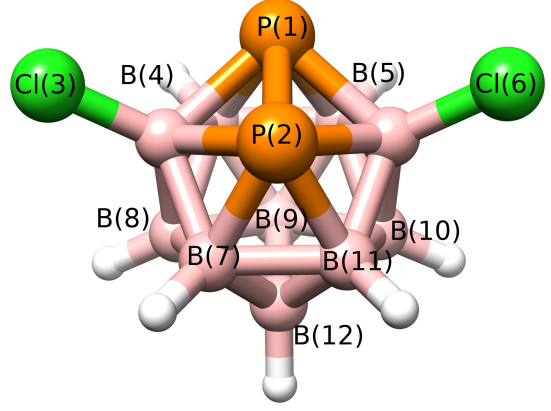

(1)

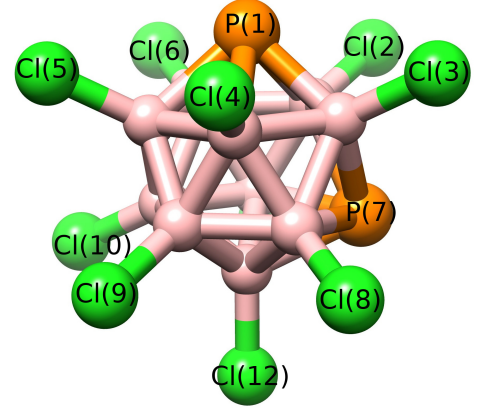

(2)

Figure 1. The molecular diagrams and numbering of $3,6-\mathrm{Cl}_{2}-$ closo-1,2- $\mathrm{P}_{2} \mathrm{~B}_{10} \mathrm{H}_{8}$ (1) and closo-1,7- $\mathrm{P}_{2} \mathrm{~B}_{10} \mathrm{Cl}_{10}$ (2).

The phosphorus atoms of closo-1,2- $\mathrm{P}_{2} \mathrm{~B}_{10} \mathrm{H}_{10}$ and closo-1,7- $\mathrm{P}_{2} \mathrm{~B}_{10} \mathrm{H}_{10}$ are incorporated into the skeleton via multicenter 3-center-2-electron (3c2e) and 4-center-2-electron (4c2e) types of bonding [5]. 
The electron distribution is in disagreement with the classical electronegativity concept in multicenter bonding [5,6] and it results in areas of highly positive electrostatic potential, called $\sigma$-holes [7], on phosphorus atoms [8]. The concept of $\sigma$-hole, developed by Politzer et al., was originally used to describe halogen $(X)$ bonds, where the $\sigma$-hole was centered on the carbon-halogen $\sigma$-bond axis. A partially positive $\sigma$-hole on a partially negative $X$ atom could thus explain the interesting ability of an $\mathrm{X}$ atom to interact simultaneously with electrophiles and nucleophiles.

Closo-phosphaboranes are not the only heteroboranes with highly positive $\sigma$-holes. Indeed, various chalcogen and $\mathrm{X}$-bonds have been reported for closo-thiaboranes and halogenated carboranes [9-11]. In addition, pnictogen (Pn) bonds are known for various nido- $\mathrm{Pn}_{2} \mathrm{C}_{2} \mathrm{~B}_{7} \mathrm{H}_{n} \mathrm{X}_{9-\mathrm{n}}$ $(\mathrm{Pn}=\mathrm{P}, \mathrm{As}, \mathrm{Sb})$ molecules [12,13]. All these $\sigma$-hole interactions have been reported for single crystalline materials. In order to expand the body of Pn-bonding in closo structural motifs, we have selected a known crystal structure of $\mathbf{1}$ [1]. Additionally, we selected the crystal of $\mathbf{2}$ cocrystalized with toluene [4] for quantum chemical analysis, the first candidate for a non-single-crystalline material in boron cluster chemistry stabilized by $\sigma$-hole interactions.

\section{Materials and Methods}

The molecular electrostatic potential (ESP) surfaces of isolated molecules $\mathbf{1}$ and $\mathbf{2}$ were computed at the Hartree-Fock (HF) level with the correlation-consistent polarized valence double-zeta (cc-pVDZ) basis set using the Gaussian09 [14] and Molekel4.3 [15,16] programs. As a one-electron property, ESP is correctly described by the non-correlated HF method and the double-zeta basis set size is sufficient for its computation [17].

Around each unique molecule in the studied crystals, we created clusters by considering the surrounding molecules. The molecules that had any atom within $5 \AA$ of the central molecule formed a cluster that was called the first layer. The second layer was obtained by considering molecules that had any atom within $5 \AA$ of the first layer. Hydrogen atoms in the central molecule and in the first layer were optimized using the density functional theory (DFT) with the resolution of identity (RI) approximation, the empirical dispersion (D3), the Becke, Lee, Yang and Parr functional (BLYP), and the double-zeta valence polarized (DZVP) basis set [18]. Hydrogen atoms of the second layer were optimized by the hybrid DFT-D3/PM6-D3H4X approach. The DFT-D3/BLYP/DZVP method was used for the first layer and the corrected semiempirical quantum mechanical PM6-D3H4X method [19] for the second layer. All heavy atoms were frozen in crystallographic positions. The obtained clusters were used for energy calculations. Two-body interaction energy $\left(\Delta E^{2}\right)$ was defined as the energy difference between the energy of the dimer and the sum of monomer energies.

$$
\Delta E^{2}(A B)=E(A B)-E(A)-E(B)
$$

Three-body energy $\left(\Delta E^{3}\right)$ was defined as the energy difference between the total energy of the trimer and the sum of both monomer energies and all $\Delta E^{2}$ values.

$$
\Delta E^{3}(A B C)=E(A B C)-E(A)-E(B)-E(C)-\Delta E^{2}(A B)-\Delta E^{2}(B C)-\Delta E^{2}(A C)
$$

Expanding the $\Delta E^{2}$ energies, the $\Delta E^{3}(\mathrm{ABC})$ could thus be expressed as:

$$
\Delta E^{3}(A B C)=E(A B C)-E(A B)-E(A C)-E(B C)+E(A)+E(B)+E(C)
$$

The sum of the $\Delta E^{2}$ values $\left(\sum \Delta E^{2}(\mathrm{~A})\right)$ of the central molecule $\mathrm{A}$ was computed for residues in the first and second layers. The whole layers were labeled as $Q$ and were formed by residues marked as $B$ to N).

$$
\sum E^{2}(\mathrm{~A})=\sum_{I=B}^{N} E^{2}(\mathrm{AI})
$$


Finally, the interaction of the central molecule A with the surrounding molecules was computed as:

$$
\Delta E(A Q)=E(A Q)-E(A)-E(Q)
$$

The many-body energy $\left(\Delta E^{M B}\right)$ was computed as the difference $\Delta E(A Q)$ and $\sum \Delta E^{2}(A)$.

$$
\Delta E^{M B}(A Q)=\Delta E(A Q)-\sum \Delta E^{2}(A)
$$

The energies were determined using the DFT-D3 method with the Tao, Perdew, Staroverov and Scuseria (TPSS) functional and the triple-zeta TZVPP basis set. Three-body dispersion was not used for the TPSS functional because it had been shown that the $\Delta \mathrm{E}^{3}$ of TPSS was too repulsive and the three-body dispersion only made the overall errors worse [20]. The benchmark $\Delta E^{2}$ were determined by the MP2.5 method [21] with the complete basis set (CBS). MP2.5/CBS was calculated as the sum of the Møller-Plesset perturbation theory to the second order (MP2) with CBS and the scaled third-order energy contribution (the scaling factor of 0.5) using the augmented correlation-consistent polarized double-zeta (aug-cc-pVDZ) basis set. For MP2/CBS, an extrapolation from aug-cc-pVDZ to aug-cc-pVTZ was used [22]. Counterpoise corrections for the basis set superposition error (BSSE) and RI approximations were used for the MP2.5 calculations. $\Delta E^{2}$ values were decomposed by symmetry-adapted perturbation-theory (SAPT) methodology. The simplest truncation of SAPT (SAPT0) decomposition [23] was performed with the recommended jun-cc-pVDZ basis sets (i.e. cc-pVDZ on hydrogen and aug-cc-pVDZ on heavier atoms) [24]. Turbomole (7.0) [25], $\mathrm{P}_{\mathrm{SI}} 4$ [26], MOPAC2016 [27] and Cuby4 [28] were used.

\section{Results and Discussion}

\subsection{The Properties of Isolated Molecules}

To obtain a deeper insight into the noncovalent interactions of phosphaboranes, we computed the ESP surfaces of $\mathbf{1}$ and $\mathbf{2}$ and compared them with analogous compounds in the literature. The parent closo-1,2- $\mathrm{P}_{2} \mathrm{~B}_{10} \mathrm{H}_{10}$ compound was reported to have highly positive $\sigma$-holes with a magnitude $\left(\mathrm{V}_{\mathrm{S}, \max }\right)$ of $22.6 \mathrm{kcal} \mathrm{mol}^{-1}$ and a large dipole moment of $2.7 \mathrm{D}$ [8]. The introduction of two electronegative $\mathrm{Cl}$ atoms in compound 1 resulted in even more positive $\sigma$-holes $\left(\mathrm{V}_{\mathrm{S}, \max }\right.$ of about $25.2 \mathrm{kcal} \mathrm{mol}^{-1}$, see Figure 2 and Table 1). The dipole moment of 1 was, however, smaller (1.2 D) because the vector addition of the two $\mathrm{B}-\mathrm{Cl}$ bond dipole moments [29] was in the opposite direction with respect to the vector pointing out from the midpoint of the $\mathrm{P}(1)-\mathrm{P}(2)$ vector towards the center of the cluster. The $\mathrm{Cl}$ atoms of $\mathbf{1}$ had slightly positive $\sigma$-holes $\left(\mathrm{V}_{\mathrm{S}, \max } 2.3 \mathrm{kcal} \mathrm{mol}^{-1}\right)$ and the minimum value of the ESP molecular surface $\left(\mathrm{V}_{\mathrm{S}, \mathrm{min}}\right)$ of the $\mathrm{Cl}(3,6)$ atom was $-9.5 \mathrm{kcal} \mathrm{mol}^{-1}$. The $\mathrm{Cl}$ atoms of $\mathbf{1}$ are thus expected to be better $\mathrm{H}$-bond acceptors than $\mathrm{X}$-bond donors.
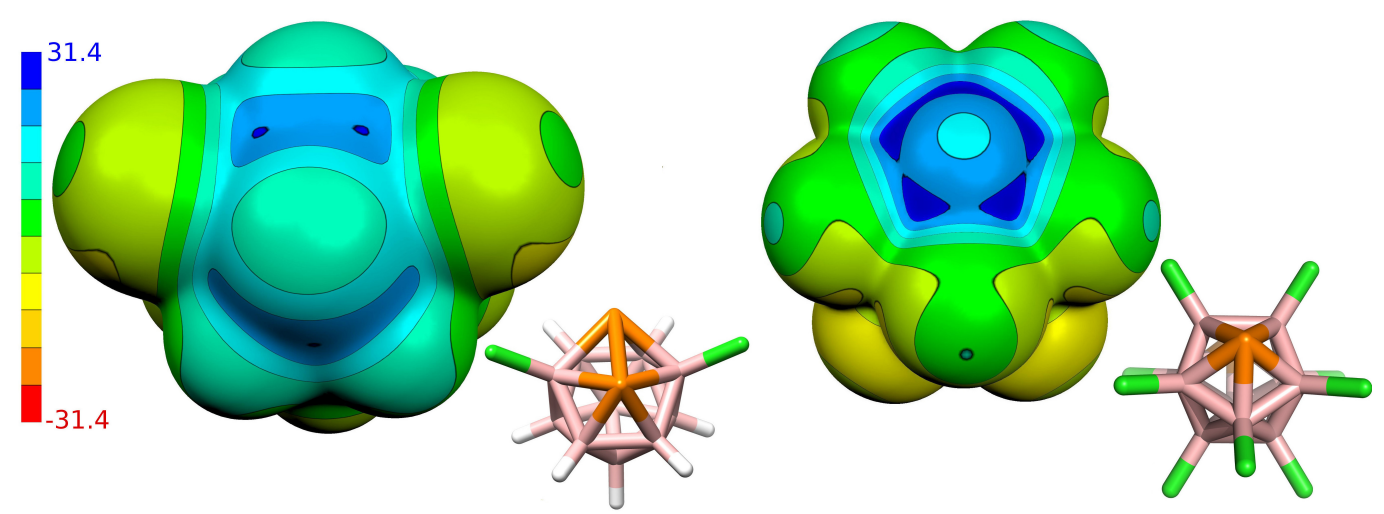

Figure 2. The computed molecular electrostatic potential (ESP) surface and molecular diagrams for 3,6-Cl $-\mathrm{Cl}_{2}$-closo-1,2- $\mathrm{P}_{2} \mathrm{~B}_{10} \mathrm{H}_{8}$ and closo-1,7- $\mathrm{P}_{2} \mathrm{~B}_{10} \mathrm{Cl}_{10}$; the color range of the ESP in $\mathrm{kcal} \mathrm{mol}^{-1}$. 
Table 1. The magnitudes of the $\sigma$-holes $\left(\mathrm{V}_{\mathrm{S}, \max }\right)$ of the $\mathrm{P}$ and $\mathrm{Cl}$ atoms.

\begin{tabular}{|c|c|c|}
\hline Compound & Atom & $\mathrm{V}_{\mathrm{S}, \max }\left[\mathrm{kcal} \mathrm{mol}^{-1}\right]$ \\
\hline \multirow{2}{*}{ 3,6-Cl $\mathrm{Cl}_{2}$-closo-1,2- $\mathrm{P}_{2} \mathrm{~B}_{10} \mathrm{H}_{8}(\mathbf{1})$} & $\mathrm{P}(1,2)$ & $2 \times 25.2 ; 25.1$ \\
\hline & $\mathrm{Cl}(3,6)^{1}$ & 2.3 \\
\hline \multirow{3}{*}{ closo-1,7- $\mathrm{P}_{2} \mathrm{~B}_{10} \mathrm{Cl}_{10}(2)$} & $\mathrm{P}(1,7)$ & $30.2 ; 2 \times 28.9 ; 2 \times 27.8$ \\
\hline & $\mathrm{Cl}(2,3)$ & 13.1 \\
\hline & $\mathrm{Cl}(9,10)^{2}$ & 1.5 \\
\hline
\end{tabular}

${ }^{1}$ The minimum value of the electrostatic potential (ESP) molecular surface of the $\mathrm{Cl}(3,6)$ atom is $-9.5 \mathrm{kcal} \mathrm{mol}^{-1} .{ }^{2}$ The minimum value of the ESP molecular surface of the $\mathrm{Cl}(9,10)$ atom is $-13.2 \mathrm{kcal} \mathrm{mol}^{-1}$.

A complete substitution of terminal hydrogens by chlorines considerably increased the dipole moment to $3.4 \mathrm{D}$ (eight $\mathrm{B}-\mathrm{Cl}$ bond dipole moments were added to the vector from the $\mathrm{P}(1)-\mathrm{P}(7)$ midpoint towards the center of the cluster) and $\mathrm{V}_{\mathrm{S}, \max }$ values up to $30.2 \mathrm{kcal} \mathrm{mol}^{-1}$ in the case of $\mathbf{2}$. It can thus be considered as a very good Pn-bond donor. Additionally, the $\mathrm{Cl}(2,3)$ atoms of $\mathbf{2}$ had positive $\sigma$-holes with a $\mathrm{V}_{\mathrm{S}, \max }$ value of $13.1 \mathrm{kcal} \mathrm{mol}^{-1}$; the $\mathrm{V}_{\mathrm{S}, \min }$ of the $\mathrm{Cl}(9,10)$ atoms was $-13.2 \mathrm{kcal} \mathrm{mol}^{-1}$. Therefore, the $\mathrm{Cl}$ atoms of $\mathbf{2}$ can act as both X-bond donors and H-bond acceptors.

\subsection{Interactions in the Single Crystal of $\mathbf{1}$ and the Crystal of $\mathbf{2} \bullet$ Toluene}

Initially, the crystal structure of $\mathbf{1}$ was analyzed. There are eight molecules in the unit cell (see Figure 3). First, all pairwise interactions were evaluated by computing interaction energy $\left(\Delta E^{2}\right)$ values by the DFT-D3 method using various functionals and basis sets. For the most stable motifs, highly accurate MP2.5/CBS $\Delta E^{2}$ values were computed. Additionally, $\Delta E^{2}$ was decomposed into different terms by using the SATP technique. The obtained results are summarized in Table 2. The SAPT0/jun-cc-pVDZ results were in reasonable agreement with the MP2.5/CBS results (the root-mean-square error (RMSE) of $0.41 \mathrm{kcal} \mathrm{mol}^{-1}$ ). Among the DFT-D3 methods, the best agreement with MP2.5/CBS results, i.e. the RMSE of $0.47 \mathrm{kcal} \mathrm{mol}^{-1}$, was found for the TPSS/TZVPP level. The other tested functionals and basis sets had a bigger RMSE, i.e. 1.31, 1.29, 1.19 and $1.10 \mathrm{kcal} \mathrm{mol}^{-1}$ for BLYP/def2-QZVP, BLYP/DZVP, B3LYP/DZVP and TPSS/DZVP, respectively. The $\Delta E^{2}$ values ranged from -3.35 to $-4.23 \mathrm{kcal} \mathrm{mol}^{-1}$ at the MP2.5/CBS level. These values are large considering that there were no intermolecular distances shorter than the sum of van der Waals radii $\left(\sum \mathrm{r}_{\mathrm{vdW}}\right)$ [30] in the crystal. The highly negative $\Delta E^{2}$ values were caused by the large dispersion contribution, which strongly dominated the interaction $(65-71 \%$ of the total attractive energy). The electrostatic interaction was also important (21-27\% of the total attractive energy). The smallest attractive term was induction ( $7-8 \%$ of the total attractive energy).

Table 2. Computed DFT-D3/TPSS/TZVPP and MP2.5/CBS two-body interaction energies for the crystal of 3,6- $\mathrm{Cl}_{2}$-closo-1,2- $\mathrm{P}_{2} \mathrm{~B}_{10} \mathrm{H}_{8}(\mathbf{1})$. Interaction energies were decomposed into electrostatic $\left(\mathrm{E}_{\text {elec }}\right)$, induction $\left(\mathrm{E}_{\mathrm{ind}}\right)$, dispersion $\left(\mathrm{E}_{\mathrm{disp}}\right)$, and exchange $\left(\mathrm{E}_{\mathrm{exch}}\right)$ contributions by SAPT0. Energies in kcal $\mathrm{mol}^{-1}$. The relative values in parentheses express the contribution to the sum of all attractive energy terms of SAPT0.

\begin{tabular}{ccccccc}
\hline \multirow{2}{*}{ Interaction } & \multirow{2}{*}{ DFT-D3/MP2.5 } & \multicolumn{5}{c}{ SAPT0/jun-cc-pVDZ } \\
\cline { 3 - 6 } & & Total & E $_{\text {elec }}$ & E $_{\text {ind }}$ & E $_{\text {disp }}$ & E $_{\text {exch }}$ \\
\hline \multirow{2}{*}{$\mathrm{A} \cdots \mathrm{B}$} & $-4.85 /-4.23$ & -4.83 & -2.28 & -0.81 & -7.67 & 5.94 \\
& & & $(21 \%)$ & $(8 \%)$ & $(71 \%)$ & \\
\multirow{2}{*}{$\mathrm{A} \cdots \mathrm{C}$} & $-4.09 /-3.90$ & -4.01 & -2.26 & -0.61 & -5.42 & 4.28 \\
& & & $(27 \%)$ & $(7 \%)$ & $(65 \%)$ & \\
\multirow{2}{*}{$\mathrm{A} \cdots \mathrm{D}$} & $-3.85 /-3.35$ & -3.70 & -2.11 & -0.65 & -5.87 & 4.92 \\
& & & $(24 \%)$ & $(8 \%)$ & $(68 \%)$ & \\
\hline
\end{tabular}




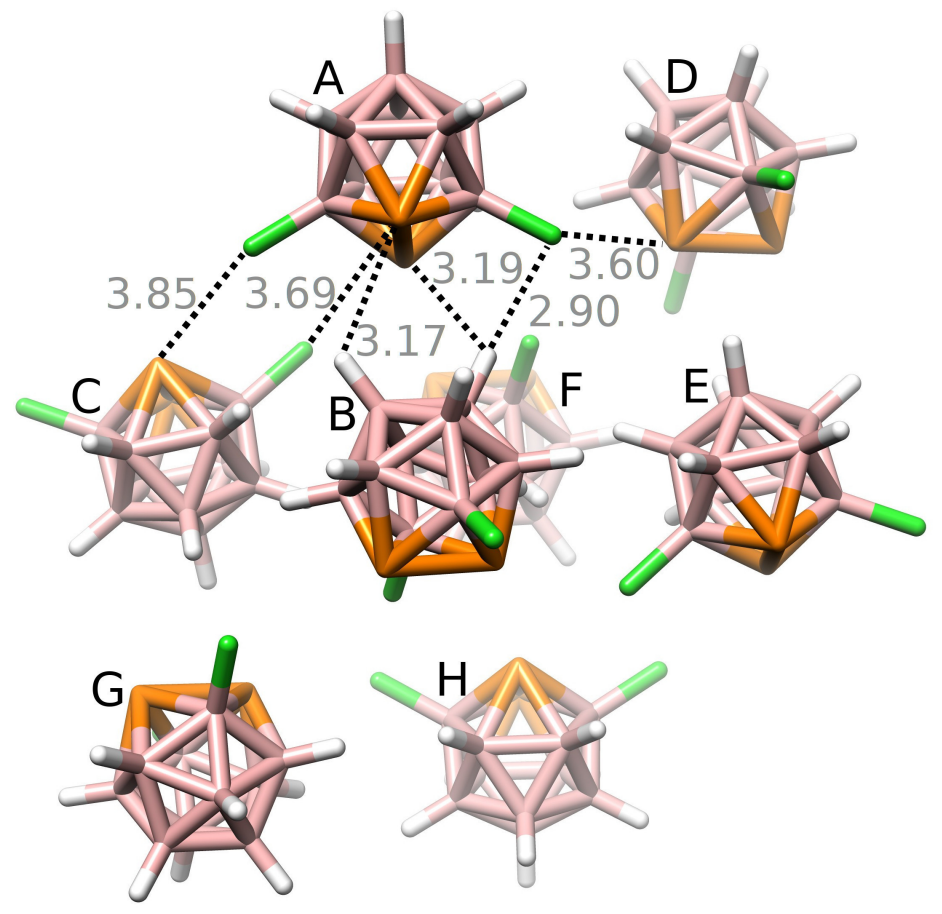

Figure 3. The crystal packing of $3,6-\mathrm{Cl}_{2}$-closo- $1,2-\mathrm{P}_{2} \mathrm{~B}_{10} \mathrm{H}_{8}$ (1). Distances in $\AA$. The color gray is used for distances larger than $\Sigma r_{v d W}$. The positions of $\mathrm{H}$ atoms were optimized at the DFT-D3/BLYP/DZVP level.

The sum of $\Delta E^{2}$ values $\left(\sum \Delta E^{2}(\mathbf{1})\right)$ was $-48.45 \mathrm{kcal} \mathrm{mol}^{-1}$ for the first layer. The consideration of the second layer made the $\sum \Delta E^{2}(\mathbf{1})$ more negative by $3.38 \mathrm{kcal} \mathrm{mol}^{-1}$. Three-body energy $\Delta E^{3}(\mathrm{ABC})$, $\Delta E^{3}(\mathrm{ACD})$ and $\Delta E^{3}(\mathrm{BCD})$ values were relatively small (below $2 \%$ of $\Delta E^{2}$ ). They ranged from -0.01 to $0.22 \mathrm{kcal} \mathrm{mol}^{-1}$ at the DFT-D3/TPSS/TZVPP level. Similar $\Delta E^{3}$ results were obtained at the DFT-D3/B3LYP/DZVP level ( $\Delta E^{3}$ ranged from -0.05 to $0.14 \mathrm{kcal} \mathrm{mol}^{-1}$ ).

Secondly, we studied interactions in the crystal of 2•toluene. The results showed that the most negative $\Delta E^{2}$ value was exhibited by the B-P $\cdots \pi$ Pn-bond. The Pn-bond was characterized by a small length of $3.08 \AA\left(88 \%\right.$ of $\left.\Sigma r_{v d W}\right)$ and its $\Delta E^{2}$ value exceeded $-10 \mathrm{kcal} \mathrm{mol}^{-1}$ at the MP2.5/CBS level (see Table 3 and Figure 4). The SAPT decomposition revealed that electrostatic and induction contributions were more important in this Pn-bond. They represented 35\% and 14\% of the total attractive energy of this Pn-bond, respectively, but they did not exceed $27 \%$ and $10 \%$ of the total attractive energy in the other interactions reported in this study. Pn $\cdots \pi$ interactions in neutral complexes are well known, especially for heavier Pn atoms (As, $\mathrm{Sb}$ and $\mathrm{Bi}$ ). For example, $\mathrm{AsCl} 3$ and $\mathrm{SbCl}_{3}$ formed $\mathrm{Pn} \cdots \pi$

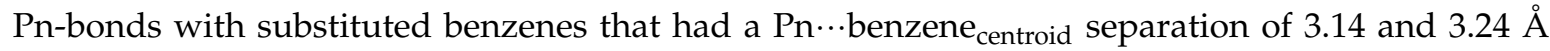
(88 and $86 \%$ of $\Sigma r_{v d W}$ ), respectively [31,32]. Phosphorus $\cdots \pi$ interactions are typically only observed in cationic phosphorus complexes, as exemplified by the interaction between the $\mathrm{Mes}^{*} \mathrm{NP}^{+}$cation

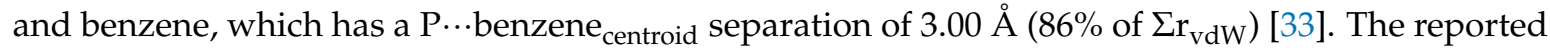
Pn-bond can be further related to analogous $\sigma$-hole interactions in heteroboranes. For example, the C-Br $\cdots \pi$ chalcogen bond reported for brominated carboranes had a length of $3.46 \AA$ (98\% of $\Sigma r_{v d W}$ ) [34] and the $\Delta E$ value of the isolated $X$-bond was estimated to be about $-4 \mathrm{kcal} \mathrm{mol}^{-1}$ [11]. The B-S $\cdots \pi$ chalcogen bond found in phenyl-substituted thiaboranes had a length of $3.24 \AA$ (93\% of $\left.\Sigma \mathrm{r}_{\mathrm{vdW}}\right)$ and a $\Delta \mathrm{E}$ of $-8.6 \mathrm{kcal} \mathrm{mol}^{-1}$ [9]. The $\mathrm{Sb}_{2} \cdots \mathrm{H}-\mathrm{B}$ Pn-bond with a length of $2.78 \AA\left(88 \%\right.$ of $\left.\Sigma \mathrm{r}_{\mathrm{vdW}}\right)$ and a $\Delta E^{2}$ of $-6.46 \mathrm{kcal} \mathrm{mol}^{-1}$ was found in the single crystal of the stibacarbaborane molecule [12]. The $\Delta E^{2}$ values of hypothetical closo-1,2- $\mathrm{P}_{2} \mathrm{~B}_{10} \mathrm{H}_{10} \cdots$ benzene, closo-1,2- $\mathrm{As}_{2} \mathrm{~B}_{10} \mathrm{H}_{10} \cdots$ benzene, and $\mathrm{AsCl}_{3} \cdot$ benzene Pn-bonded complexes were computed and reported to be $-4.8,-5.6$ and $-6.5 \mathrm{kcal}$ $\mathrm{mol}^{-1}$, respectively [8,35]. 
The computed $\sum \Delta E^{2}$ values were used to evaluate the importance of the B-P $\cdots \pi$ Pn-bond for the crystal packing of $2 \bullet$ toluene. The $\sum \Delta E^{2}$ (toluene) and $\sum \Delta E^{2}(\mathbf{2})$ were -31.55 and $-57.12 \mathrm{kcal} \mathrm{mol}^{-1}$ for the first layer, respectively. The B-P $\cdots \pi$ Pn-bonds thus formed 63 and $35 \%$ of $\sum \Delta E^{2}$ (toluene) and $\sum \Delta E^{2}(2)$, respectively. The consideration of the second layer made $\sum \Delta E^{2}$ (toluene) and $\sum \Delta E^{2}(2)$ more negative by about 1.98 and $5.13 \mathrm{kcal} \mathrm{mol}^{-1}$, which lowered the relative contribution of Pn-bonds to $60 \%$ and $32 \%$, respectively. Additionally, the computed $\Delta E^{3}$ values of the Pn-bonds were more repulsive than for those of the other interactions. The $\Delta E^{3}$ (2toluene2) and $\Delta E^{3}$ (toluene2toluene) sandwich-like motifs stabilized by the Pn-bond were 1.34 and $0.36 \mathrm{kcal} \mathrm{mol}^{-1}$, respectively, at the DFT-D3/TPSS/TZVPP level. The $\Delta E^{3}$ thus further reduced the strength of the Pn-bonding by about $7 \%$. The other interactions were reduced by less than $2 \%$ by the $\Delta E^{3}$. The role of many-body energies was further examined by computing the $\Delta \mathrm{E}^{\mathrm{MD}}$ for the toluene cluster (the first layer considered). The obtained value of $2.64 \mathrm{kcal} \mathrm{mol}^{-1}$ represented $8 \%$ of the $\sum \Delta E^{2}$ (toluene) value. Summarizing the results shown above, the Pn-bond formed about 56 and $32 \%$ of the computed binding energy for the toluene and 2, respectively. These results indicate the large importance of Pn-bonding, especially for toluene. Interestingly, the diX-bonds represented about $42 \%$ of the computed binding of 2 , which was even more than that of Pn-bonding in this case. Even though the diXbonds were considerably weaker than the Pn-bonds (see Table 3), they were much more numerous, which resulted in an overall large contribution to the computed binding energy.

Table 3. Computed DFT-D3/TPSS/TZVPP and MP2.5/CBS two-body interaction energies for the

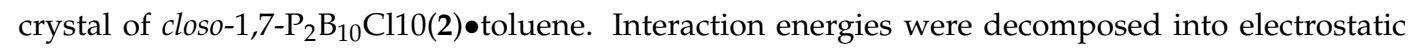
$\left(E_{\text {elec }}\right)$, induction $\left(E_{\text {ind }}\right)$, dispersion $\left(E_{\text {disp }}\right)$, and exchange $\left(E_{\text {exch }}\right)$ contributions by SAPT0. Energies in $\mathrm{kcal} \mathrm{mol}^{-1}$. The relative values in parentheses express the contribution to the sum of all attractive energy terms of SAPT0.

\begin{tabular}{|c|c|c|c|c|c|c|}
\hline \multirow{2}{*}{ Interaction } & \multirow{2}{*}{ DFT-D3/MP2.5 } & \multicolumn{5}{|c|}{ SAPT0/jun-cc-pVDZ } \\
\hline & & Total & $\mathrm{E}_{\text {elec }}$ & $E_{\text {ind }}$ & $\mathrm{E}_{\text {disp }}$ & $\mathrm{E}_{\text {exch }}$ \\
\hline $2 \cdots$ toluene Pn-bond & $-9.94 /-10.55$ & -11.56 & $\begin{array}{l}-9.80 \\
(35 \%)\end{array}$ & $\begin{array}{l}-3.96 \\
(14 \%)\end{array}$ & $\begin{array}{l}-14.61 \\
(52 \%)\end{array}$ & 16.81 \\
\hline $2 \cdots$ toluene stacking & $-2.51 /-2.25$ & -1.96 & $\begin{array}{l}-0.84 \\
(22 \%)\end{array}$ & $\begin{array}{l}-0.21 \\
(6 \%)\end{array}$ & $\begin{array}{l}-2.75 \\
(72 \%)\end{array}$ & 1.84 \\
\hline $2 \cdots$ toluene $\mathrm{H}$-bond & $-0.87 /-0.80$ & -0.51 & $\begin{array}{l}-0.35 \\
(16 \%)\end{array}$ & $\begin{array}{l}-0.21 \\
(10 \%)\end{array}$ & $\begin{array}{l}-1.58 \\
(74 \%)\end{array}$ & 1.63 \\
\hline $2 \cdots 2$ bifurcated diX-bonds & -3.67 & -3.27 & $\begin{array}{l}-1.17 \\
(16 \%)\end{array}$ & $\begin{array}{l}-0.32 \\
(4 \%)\end{array}$ & $\begin{array}{l}-5.73 \\
(79 \%)\end{array}$ & 3.95 \\
\hline $2 \cdots 2$ bifurcated diX-bond & -2.94 & -3.01 & $\begin{array}{l}-1.78 \\
(26 \%)\end{array}$ & $\begin{array}{c}-0.40 \\
(6 \%)\end{array}$ & $\begin{array}{l}-4.67 \\
(68 \%)\end{array}$ & 3.84 \\
\hline $2 \cdots 2$ diX-bond & $-2.32 /-2.65$ & -2.13 & $\begin{array}{l}-1.51 \\
(25 \%)\end{array}$ & $\begin{array}{c}-0.35 \\
(6 \%)\end{array}$ & $\begin{array}{l}-4.13 \\
(69 \%)\end{array}$ & 3.86 \\
\hline
\end{tabular}

The shortest intermolecular $\mathrm{Cl} \cdots \mathrm{Cl}$ separation in the crystal structure was $3.38 \AA$ ( $96 \%$ of $\left.\Sigma \mathrm{r}_{\mathrm{vdW}}\right)$. The diX-bond had $\Delta E^{2}$ of $-2.65 \mathrm{kcal} \mathrm{mol}^{-1}$ at the MP2.5/CBS level. The geometrical arrangement of this interaction had very similar $\Theta_{1}$ and $\Theta_{2}$ angles (i.e. B-Cl $\cdots \mathrm{Cl}$ angles of $125^{\circ}$ and $127^{\circ}$ ), which is typical of diX-bonds [36]. Additionally, H-bonding can also be found in the crystal of 2॰toluene. The $\mathrm{H}$-bond had the least negative $\Delta E^{2}$ value among the interaction motifs in this study and the $\mathrm{H} \cdots \mathrm{Cl}$ distance was $2.74 \AA$ ( $96 \%$ of $\left.\Sigma r_{v d W}\right)$.

In summary, we analyzed noncovalent interactions in the single crystal of $\mathbf{1}$ and in the crystal of 2॰toluene by quantum chemical protocols. The analysis revealed numerous diXbonds and unusually

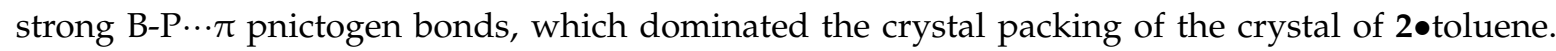
The Pn-bond length was significantly below $\Sigma \mathrm{r}_{\mathrm{vdW}}$ and the $\Delta \mathrm{E}$ value overcoming $-10 \mathrm{kcal} \mathrm{mol}^{-1}$. 


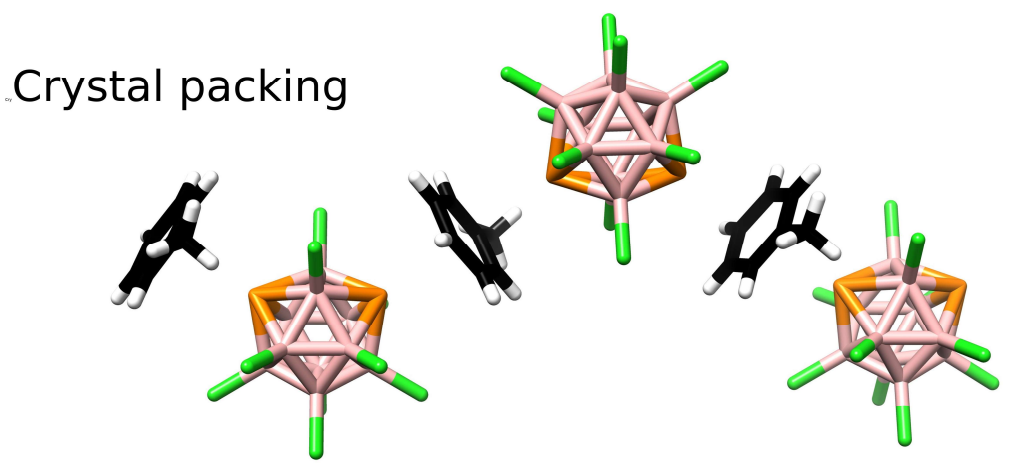

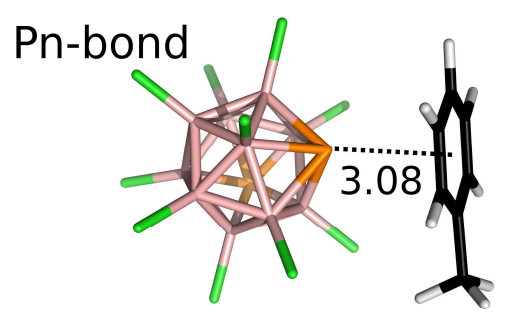

H-bond

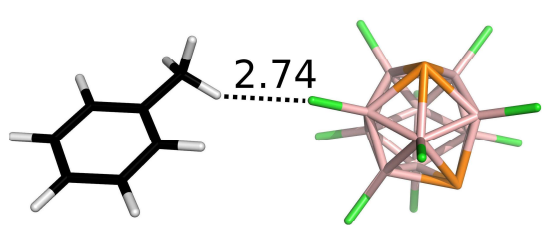

Bifurcated diX-bond

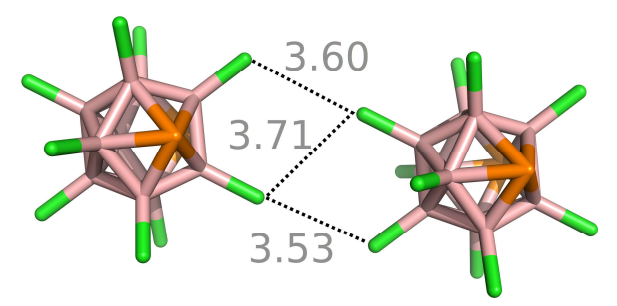

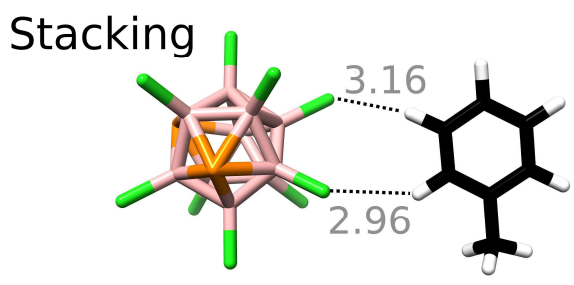

Bifurcated diX-bonds

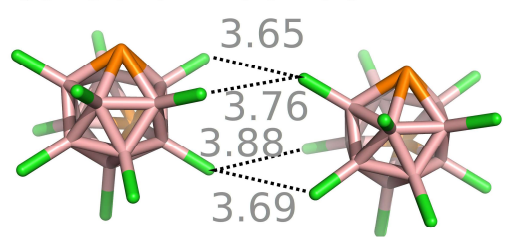

diX-bond

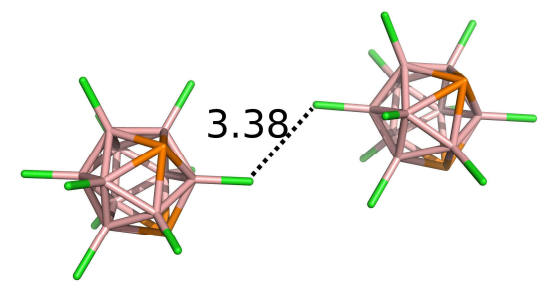

Figure 4. The crystal packing and binding motifs of closo-1,7- $\mathrm{P}_{2} \mathrm{~B}_{10} \mathrm{Cl}_{10} \bullet$ toluene. Distances in $\AA$. The color gray is used for distances larger than $\Sigma r_{v d W}$. The positions of $\mathrm{H}$ atoms were optimized at the DFT-D3/BLYP/DZVP level.

Author Contributions: Methodology, J.F. and D.H.; Writing Draft Preparation, J.F. and D.H.; Visualization, J.F.; Project Administration, J.F. and D.H.

Funding: This work was supported by the research project RVO 61388963 of the Czech Academy of Sciences. This research was funded by the Czech Science Foundation grant number 17-08045S.

Conflicts of Interest: The authors declare no conflicts of interest.

\section{References}

1. Grüner, B.; Hnyk, D.; Císařová, I.; Plzák, Z.; Štíbr, B. Phosphaborane Chemistry. Syntheses and Calculated Molecular Structures of Mono- and Di-chloro Derivatives of 1,2-Diphospha-closo-dodecaborane(10). J. Chem. Soc. Dalton Trans. 2002, 15, 2954-2959. [CrossRef]

2. Štíbr, B.; Holub, J.; Bakardjiev, M.; Hnyk, D.; Tok, O.L.; Milius, W.; Wrackmeyer, B. Phosphacarborane Chemistry: The Synthesis of the Parent Phosphadicarbaboranes nido-7,8,9- $\mathrm{PC}_{2} \mathrm{~B}_{8} \mathrm{H}_{11}$ and [nido-7,8,9- $\left.\mathrm{PC}_{2} \mathrm{~B}_{8} \mathrm{H}_{10}\right]^{-}$, and Their 10-Cl Derivatives-Analogs of the Cyclopentadiene Anion. Eur. J. Inorg. Chem. 2002, 9, 2320-2326. [CrossRef] 
3. Little, J.L.; Whitesell, M.A.; Chapman, R.W.; Kester, J.G.; Huffman, J.C.; Todd, L.J. Synthesis of Some 10-, 11-, and 12-Atom Phosphaboranes. Crystal Structure of 2-(Trimethylamine)-1- $\mathrm{PB}_{11} \mathrm{H}_{10}$. Inorg. Chem. 1993, 32, 3369-3372. [CrossRef]

4. Keller, W.; Sawitzki, G.; Haubold, W. Synthesis of Halogenated Polyhedral Phosphaboranes. Crystal Structures of closo-1,7- $\mathrm{P}_{2} \mathrm{~B}_{10} \mathrm{Cl}_{10}$. Inorg. Chem. 2000, 39, 1282-1287. [CrossRef] [PubMed]

5. Melichar, P.; Hnyk, D.; Fanfrlík, J. Systematic Examination of Classical and Multi-Center Bonding in Heteroborane Clusters. Phys. Chem. Chem. Phys. 2018, 20, 4666-4675. [CrossRef] [PubMed]

6. Hnyk, D.; Všetečka, V.; Drož, L.; Exner, O. Charge Distribution within 1,2-Dicarba-closo-dodecaborane: Dipole Moments of its Phenyl Derivatives. Collect. Czech. Chem. Commun. 2001, 66, 1375-1379. [CrossRef]

7. Clark, T.; Hennemann, M.; Murray, J.S.; Politzer, P. Halogen Bonding: The $\sigma$-Hole. J. Mol. Model. 2007, 13, 291-296. [CrossRef] [PubMed]

8. Pecina, A.; Lepšík, M.; Hnyk, D.; Hobza, P.; Fanfrlík, J. Chalcogen and Pnicogen Bonds in Complexes of Neutral Icosahedral and Biccaped Square-Antiprismatic Heteroboranes. J. Phys. Chem. A 2015, 119, 1388-1395. [CrossRef] [PubMed]

9. Fanfrlík, J.; Přáda, A.; Padělková, Z.; Pecina, A.; Macháček, J.; Lepšík, M.; Holub, J.; Růžička, A.; Hnyk, D.; Hobza, P. The Dominant Role of Chalcogen Bonding in the Crystal Packing of 2D/3D Aromatics. Angew. Chem. Int. Ed. 2014, 53, 10139-10142. [CrossRef] [PubMed]

10. Fanfrlík, J.; Hnyk, D. Chalcogens Act as Inner and Outer Heteroatoms in Borane Cages with Possible Consequences for $\sigma$-Hole Interactions. CrystEngComm 2016, 47, 8973-9162. [CrossRef]

11. Fanfrlík, J.; Holub, J.; R̛̊žičková, Z.; Řezáč, J.; Lane, P.D.; Wann, D.A.; Hnyk, D.; Růžička, A.; Hobza, P. Competition between Halogen, Hydrogen and Dihydrogen Bonding in Brominated Carboranes. ChemPhysChem 2016, 17, 3373-3376.

12. Holub, J.; Melichar, P.; Růžičková, Z.; Vrána, J.; Wann, D.A.; Fanfrlík, J.; Hnyk, D.; Růžička, A. A Novel Stibacarbaborane Cluster with Adjacent Antimony Atoms Exhibiting Unique Pnictogen Bond Formation that Dominates Its Crystal Packing. Dalton Trans. 2017, 46, 13714-13719. [CrossRef] [PubMed]

13. Holub, J.; Růžičková, Z.; Hobza, P.; Fanfrlík, J.; Hnyk, D.; Růžička, A. Various Types of Non-covalent Interactions Contributing Towards Crystal Packing of Halogenated Diphospha-dicarborane with an Open Pentagonal Belt. New J. Chem. 2018, 42, 10481-10483. [CrossRef]

14. Frisch, M.J.; Trucks, G.W.; Schlegel, H.B.; Scuseria, G.E.; Robb, M.A.; Cheeseman, J.R.; Scalmani, G.; Barone, V.; Mennucci, B.; Petersson, G.A.; et al. Gaussian 09, Revision, D.01; Gaussian, Inc.: Wallingford, CT, USA, 2009.

15. Flúkiger, P.; Lúthi, H.P.; Portmann, S.; Weber, J. MOLEKEL 4.3; Swiss Center for Scientific Computing: Manno, Switzerland, 2000.

16. Portmann, S.; Luthi, H.P. MOLEKEL: An Interactive Molecular Graphic Tool. CHIMIA Int. J. Chem. 2000, 54, 766-770.

17. Riley, K.E.; Tran, K.A.; Lane, P.; Murray, J.S.; Politzer, P. Comparative Analysis of Electrostatic Potential Maxima and Minima on Molecular Surfaces, as Determined by Three Methods and a Variety of Basis Sets. J. Comput. Sci. 2016, 17, 273-284. [CrossRef]

18. Hostaš, J.; Řezáč, J. Accurate DFT-D3 Calculations in a Small Basis Set. J. Chem. Theory Comput. 2017, 13, 3575-3585. [CrossRef] [PubMed]

19. Ǩezáč, J.; Hobza, P. Advanced Corrections of Hydrogen Bonding and Dispersion for Semiempirical Quantum Mechanical Methods. J. Chem. Theory Comput. 2012, 8, 141-151. [CrossRef] [PubMed]

20. Ǩezáč, J.; Huang, Y.; Hobza, P.; Beran, J.O.G. Benchmark Calculations of Three-Body Intermolecular Interactions and the Performance of Low-Cost Electronic Structure Methods. J. Chem. Theory Comput. 2015, 11, 3065-3079. [CrossRef] [PubMed]

21. Pitonak, M.; Neogady, P.; Cerny, J.; Grimme, S.; Hobza, P. Scaled MP3 Non-Covalent Interaction Energies Agree Closely with Accurate CCSD(T) Benchmark Data. ChemPhysChem 2009, 10, 282-289. [CrossRef] [PubMed]

22. Halkier, A.; Helgaker, T.; Jørgensen, P.; Klopper, W.; Koch, H.; Olsen, J.; Wilson, A.K. Basis-Set Convergence in Correlated Calculations on $\mathrm{Ne}_{2} \mathrm{~N}_{2}$, and $\mathrm{H}_{2} \mathrm{O}$. Chem. Phys. Lett. 1998, 286, 243-252. [CrossRef]

23. Jeziorski, B.; Moszynski, R.; Szalewicz, K. Perturbation Theory Approach to Intermolecular Potential Energy Surfaces of van der Waals Complexes. Chem. Rev. 1994, 94, 1887-1930. [CrossRef] 
24. Parker, T.M.; Burns, L.A.; Parrish, R.M.; Ryno, A.G.; Sherrill, C.D. Levels of Symmetry Adapted Perturbation Theory (SAPT). I. Efficiency and Performance for Interaction Energies. J. Chem. Phys. 2014, 140, 094106. [CrossRef] [PubMed]

25. Ahlrichs, R.; Bar, M.; Haser, M.; Horn, H.; Kolmel, C. Electronic Structure Calculations on Workstation Computers: The Program System Turbomole. Chem. Phys. Lett. 1989, 162, 165-169. [CrossRef]

26. Turney, J.M.; Simmonett, A.C.; Parrish, R.M.; Hohenstein, E.G.; Evangelista, F.; Fermann, J.T.; Mintz, B.J.; Burns, L.A.; Wilke, J.J.; Abrams, M.L.; et al. Psi4: An Open-Source Ab Initio Electronic Structure Program. WIREs Comput. Mol. Sci. 2012, 2, 556-565. [CrossRef]

27. Stewart, J.P. Optimization of parameters for semiempirical methods IV: Extension of MNDO, AM1, and PM3 to more main group elements. J. Mol. Model. 2004, 10, 155-164. [CrossRef] [PubMed]

28. Ǩezáč, J. Cuby: An Integrative Framework for Computational Chemistry. J. Comput. Chem. 2016, 37, 1230-1237. [CrossRef] [PubMed]

29. Macháček, J.; Plešek, J.; Holub, J.; Hnyk, D.; Všetečka, V.; Císařová, I.; Kaupp, M.; Štíbr, B. New Route to 1-Thia-closo-dodecaborane(11), closo-1- $\mathrm{SB}_{11} \mathrm{H}_{11}$, and Its Halogenation Reactions. The Effect of the Halogen on the Dipole Moments and the NMR Spectra and the Importance of Spin-Orbit Coupling for the ${ }^{11} \mathrm{~B}$ Chemical Shifts. Dalton Trans. 2006, 1024-1029.

30. Mantina, M.; Chamberlin, A.C.; Valero, R.; Cramer, C.J.; Truhlar, D.G. Consistent van der Waals Radii for the Whole Main Group. J. Phys. Chem. A 2009, 113, 5806-5812. [CrossRef] [PubMed]

31. Schmidbaur, H.; Nowak, R.; Steigelmann, O.; Muller, G. $\pi$-Complexes of p-Block Elements: Synthesis and Structures of Adducts of Arsenic and Antimony Halides with Alkylated Benzenes. Chemische Berichte 1990, 123, 1221-1226. [CrossRef]

32. Burford, N.; Clyburne, J.A.C.; Wiles, J.A.; Cameron, T.S.; Robertson, K.N. Tethered Diarenes as Four-Site Donors to $\mathrm{SbCl}_{3}$. Organometallics 1996, 15, 361-364. [CrossRef]

33. Burford, N.; Clyburne, J.A.C.; Bakshi, P.K.; Cameron, T.S. $\eta^{6}$-Arene Complexation to a Phosphenium Cation. J. Am. Chem. Soc. 1993, 115, 8829-8830. [CrossRef]

34. McGrath, T.D.; Welch, A.J. Steric Effects in Heteroboranes. IV. 1-Ph-2-Br-1,2-closo- $\mathrm{C}_{2} \mathrm{~B}_{10} \mathrm{H}_{10}$. Acta Cryst. 1995, C51, 649-651. [CrossRef]

35. Bauzá, A.; Quiñonero, D.; Deyà, P.M.; Frontera, A. Halogen Bonding versus Chalcogen and Pnicogen Bonding: A Combined Cambridge Structural Database and Theoretical Study. CrystEngComm 2013, 15, 3137-3144. [CrossRef]

36. Awwadi, F.F.; Willet, R.D.; Peterson, K.A.; Twamley, B. The Nature of Halogen $\cdots$ Halogen Synthons: Crystalographic and Theoretical Studies. Chem. Eur. J. 2006, 12, 8952-8960. [CrossRef] [PubMed] 